\title{
Advantages of the use of heterogeneous catalyst for Huisgen cycloaddition reaction: synthesis and application of new metalorganic material capable of regeneration and reuse
}

\author{
Mônica Freire Belian ${ }^{+1}$, Wagner Eduardo da Silva ${ }^{1}$, Moara Targino da Silva ${ }^{1}$, Aline de Andrade Alves ${ }^{1}$, Ronaldo \\ Nascimento de Oliveira ${ }^{1}$, \\ ${ }^{1}$ University Federal Rural de Pernambuco (UFRPE), Dom Manuel Medeiros St, Recife, Pernambuco, Brazil \\ + Corresponding author: Mônica Freire Belian, phone: +55 813320 6370, e-mail address: monica.freirebelian@ufrpe.br
}

\section{ARTICLE INFO}

\section{Article history:}

Received: December 28, 2017

Accepted: May 18, 2018

Published: May 29, 2018

\author{
Keywords: \\ 1. Huisgen cycloaddition \\ 2. copper catalysis \\ 3. triazole \\ 4. click chemistry
}

ABSTRACT: This works evaluates the catalytic capacity of metalorganic materials synthesized, based on $\mathrm{Cu}^{+}$and ambidentade ligand in Huisgen cycloaddition reaction. The synthesis of 1,2,3-triazole was made using $\mathrm{CuCl}$ and $\mathrm{CuI}$ salts, and the $\left[\mathrm{Cu}\left(4,4^{\prime}-\right.\right.$ dipy $\left.)\right] \mathrm{Cl}$ and $\left[\mathrm{Cu}\left(4,4^{\prime}\right.\right.$-dipy $\left.)\right] \mathrm{I}$ compounds as catalysts, with or without base catalysis by triethylamine. The copper salts and compounds lead to formation of the desired triazole product; however, in the synthesis mediated by [Cu(4,4'-dipy)]I does not generate the product, even after $48 \mathrm{~h}$ of reaction. The reaction with $\left[\mathrm{Cu}\left(4,4^{\prime}\right.\right.$-dipy $\left.)\right] \mathrm{Cl}$ mediated or not by triethylamine showed high yields of $88 \%$ and $70 \%$, respectively. The [Cu(4,4'-dipy) $] \mathrm{Cl}$ compounds was reused five times, and regenerated by ascorbic acid, maintaining thus, the same reaction yield.

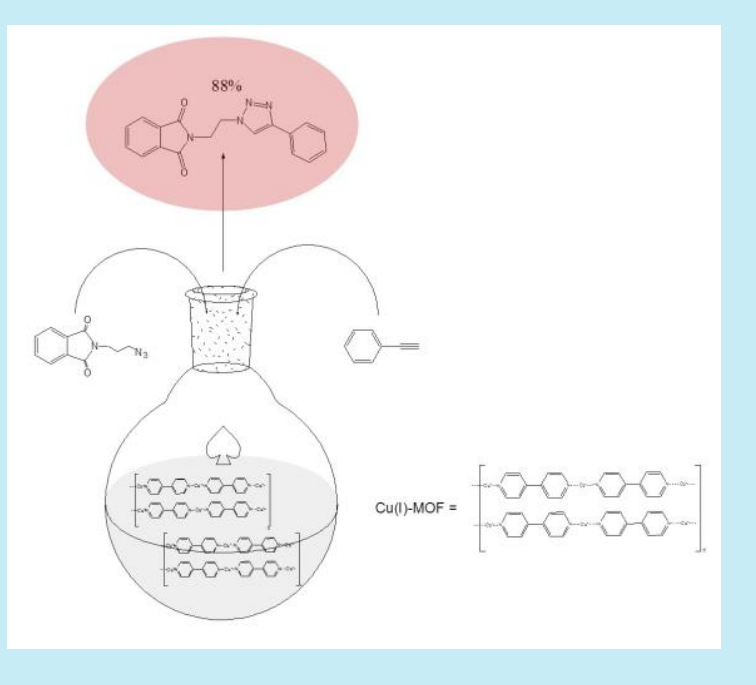

\section{Introduction}

Metalorganic materials have attracted attention owing to their potential applications in gas separation and storage ${ }^{1}$, as sensors ${ }^{2}$, in drug storage and delivery ${ }^{3}$, templated low-dimensional material preparations ${ }^{4}$, and principally, as catalysts ${ }^{5}$. Due to their high surface areas, pore sizes, ease and diversity of their ability to process, these compounds can be used in catalysis. The literature reports on several works that describe very recently the use of metalorganic materials as catalysts in solid-phase organic reactions, such as in FriedelCrafts alkylation and acylation ${ }^{6-8}$, oxidation ${ }^{9-14}$, alkene epoxidation ${ }^{15-17}$, hydrogenation ${ }^{18}$, Suzuki cross-coupling $^{19},{ }^{20}$, the Sonogashira reaction ${ }^{21}$, transesterification reaction ${ }^{22}$, the Knoevenagel condensation $^{23-25}$, aldol condensation ${ }^{26},{ }^{27}$ and 1,3dipolar cycloaddition reactions ${ }^{28}$. The Huisgen azide-alkyne 1,3-dipolar cycloaddition afford 1,2,3-triazole derivatives, through solid-phase catalyst that has a number of advantages, such as low consumption of reagents and solvents, possibility of regeneration and removal of the 
catalyst from the reaction medium. In this context, metalorganic materials are widely used because of these advantages. The literature describes the use these compounds, for instance in cyclization reaction ${ }^{29}$; however, some catalysts, it is shown low yields, difficulty in the removal of residues, as well as the impossibility of catalyst reuse. An explanation for these problems is the use of copper (II) ion, to constitute the metalorganic structure, since the 1,3-dipolar cycloaddition reaction needs the presence of copper(I) ions. The copper(I) catalyst promotes the formation of 1,2,3-triazoles from azides and terminal alkynes, with high yields, mild conditions and excellent regioselectivity ${ }^{30,31}$. Generally, in this reaction, the desired product is isolated by chromatography and the copper(I) residues are removed by an extraction process, using successive washes with ammonium hydroxide ${ }^{32,33}$.

In this work were synthesized and characterized copper(I) complexes containing 4,4'-dipyridyl (4,4'-dipy) as ligand, and $\mathrm{CuCl}$ or $\mathrm{CuI}$ as copper (I) font. To reduce the number of extraction steps and low yields, and to promote the reuse of the catalyst, we used two copper(I) compounds as catalysts in solid-phase for reaction between phenylacetylene $(\mathrm{PhA})$ and 2-[2-azido-ethyl]-isoindole-1,3-dione (AID) in the presence or absence of base (triethylamine). The reactions were repeated five times and the catalyst was reuse, through of the regeneration process by ascorbic acid.

\section{Materials and methods}

The copper(I) chloride, copper(I) iodide, 4,4'dipyridyl, triethylamine, dichloromethane, phenylacetylene and 2-[2-azido-ethyl]-isoindole1,3-dione (all from Aldrich) were all used as received. Carbon, nitrogen and hydrogen percentages for the two metalorganic compounds and 1,2,3-triazole were determined by analysis of the elements, using a Perkin-Elmer Model 240 microanalyzer. The infrared spectra were obtained with a KBr tablet using a Fourier transform IF66 model spectrophotometer in the $4000-400 \mathrm{~cm}^{-1}$ range, with a spectral resolution of $4 \mathrm{~cm}^{-1}$. The NMR spectrum was obtained using VARIAN Unity Plus 300 equipment, at frequencies of 400
$\mathrm{MHz}$ to ${ }^{1} \mathrm{H}$ in DMSO and $75.5 \mathrm{MHz}$ to ${ }^{13} \mathrm{C}$ in $\mathrm{CDCl}_{3}$.

\subsection{Synthesis of Copper(I) complexes}

The optimized synthesis of copper(I) complexes in the reactor system $\left(\mathrm{V}_{\max }=5.0 \mathrm{~mL}\right.$ per Teflon insert) is as follows: $0.5 \mathrm{mmol}$ of $\mathrm{CuCl}(49.5 \mathrm{mg})$ or $\mathrm{CuI}(95.25 \mathrm{mg})$ and $0.5 \mathrm{mmol}$ of 4,4'-dipyridyl $(78.0 \mathrm{mg})$ were dissolved in $4 \mathrm{~mL}$ dried ethanol $(0.068 \mathrm{mmol})$. The reactor was heated for $24 \mathrm{~h}$ at $120^{\circ} \mathrm{C}$. After the reaction, the resultant solid was filtered and washed with water and ethanol three times. The powder obtained was then dried at room temperature in a fume hood and then dried under vacuum at $40{ }^{\circ} \mathrm{C}$ for $4 \mathrm{~h}$.

\subsection{Synthesis of 1,4-disubstituted 1,2,3-triazole}

In a test tube, $100 \mathrm{mg}(0.5 \mathrm{mmol})$ of 2-[2-azidoethyl]-isoindole-1,3-dione, $71 \mathrm{mg}(1.5 \mathrm{mmol})$ of phenylacetylene, $10 \mathrm{~mol} \%(12 \mathrm{mg})$ of catalyst ([Cu(4,4'-dipy)]Cl, [Cu(4,4'-dipy)]I, $\mathrm{CuCl}$ or $\mathrm{CuI})$ and $10 \mathrm{~mol} \%$ (6 $\mathrm{mg} \sim 1 \mathrm{drop})$ triethylamine or $(8$ $\mathrm{mg}$ ) ascorbic acid were mixed together in $1.2 \mathrm{~mL}$ of dichloromethane (see Scheme 1). The same mixture was used either without the base or without the acid. Each mixture was stirred at room temperature $(298 \mathrm{~K})$ in an argon atmosphere; and monitored by TLC (Hexane:EtOAc, 8:2). After the consumption of the starting material, the mixture was decanted using centrifugation and washed. Thereafter, the supernatant was subjected to drying by adding sodium sulfate, and then filtered. The filtrate was crystallized and the final product was analyzed by ${ }^{1} \mathrm{H}$ and ${ }^{13} \mathrm{C}$ NMR, infrared spectroscopy and elemental analysis to verify the synthesis of triazole by use of metalorganic compounds.

\section{Results and discussion}

In the synthesis of copper(I) complexes, a light green (from $\mathrm{CuCl}$ reagent) and a red (from $\mathrm{CuI}$ reagent) precipitant with crystalline characteristics were generated. The elemental analysis data of the $\left[\mathrm{Cu}\left(4,4^{\prime}\right.\right.$ '-dipy $\left.)\right] \mathrm{Cl}$ and $\left[\mathrm{Cu}\left(4,4^{\prime}\right.\right.$-dipy $\left.)\right] \mathrm{I}$ complexes are shown in Table 1. 
Table 1. Elemental analysis data of copper(I) complexes

\begin{tabular}{lllllll}
\hline Minimal Formulae & $\mathbf{\%} \mathbf{C}$ & \multicolumn{9}{c}{$\mathbf{H}$} & $\mathbf{\% N}$ \\
& $\mathbf{E}$ & $\mathbf{T}$ & $\mathbf{E}$ & $\mathbf{T}$ & $\mathbf{E}$ & $\mathbf{T}$ \\
\hline$\left[\mathrm{Cu}_{\mathrm{x}}\left(4,4^{\prime} \text {-dipy }\right)\right]_{\mathrm{n}} \mathrm{Cl}_{\mathrm{x}}$ & 47.10 & 47.06 & 3.16 & 3.14 & 11.02 & 10.98 \\
{$\left[\mathrm{Cu}_{\mathrm{x}}\left(4,4^{\prime} \text {-dipy }\right)\right]_{\mathrm{n}} \mathrm{I}_{\mathrm{x}}$} & 34.65 & 34.63 & 2.31 & 2.31 & 8.12 & 8.08 \\
\hline$* 4,4^{\prime}$-dipy $=4,4^{\prime}$-dipyridyl, E =Experimental and $\mathrm{T}=$ Theoretical.
\end{tabular}

The CHN elemental analysis results are in good agreement with the proposed formulas for the copper(I) complexes; with an error level less than $0.4 \%$ (Table 1). The infrared spectroscopy was complementarily used through the assignment of bands to functional groups of the free ligands as well as with the possible band shifts which could be correlated with the copper ion coordination. In Figure 1, the infrared overlapped spectra of the $[\mathrm{Cu}(4,4$ '-dipy $)] \mathrm{Cl}$ and 4,4'-dipyridyl ligand are presented. Since the $\left[\mathrm{Cu}\left(4,4^{\prime}\right.\right.$-dipy $\left.)\right] \mathrm{I}$ had the same spectral profile, this has not been dealt with in this text.

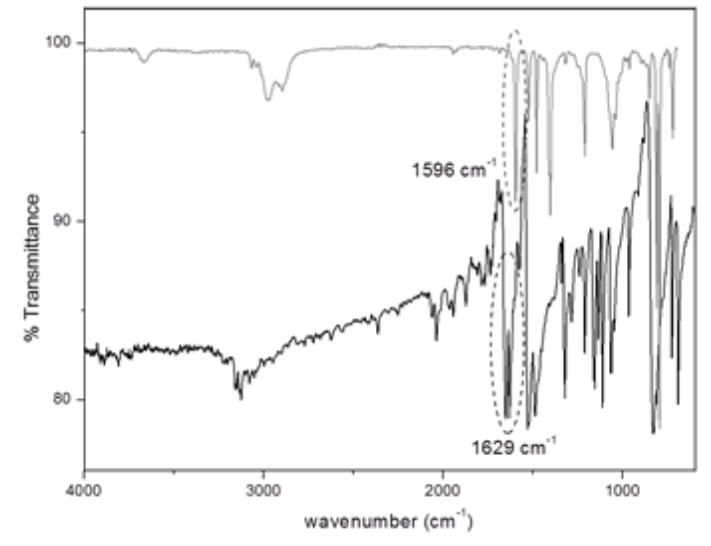

Figure 1. Infrared spectra of $4,4^{`}$-dipyridyl (in black) and $[\mathrm{Cu}(4,4$ '-dipy) $] \mathrm{Cl}$ complex (in gray).

It can be observed that the $\mathrm{C}=\mathrm{N}$ stretch of the $\left[\mathrm{Cu}\left(4,4^{\prime}\right.\right.$-dipy $\left.)\right] \mathrm{Cl}$ complex $\left(1596 \mathrm{~cm}^{-1}\right)$ are shifted to the red region in comparison to the free ligand $\left(1629 \mathrm{~cm}^{-1}\right)$, suggesting coordination with the copper (I) ion. In the absence of an X-ray structural analysis, because the mixture had polycrystalline properties, structure based on elemental analysis data and infrared spectroscopy could be suggested (see Figure 2).

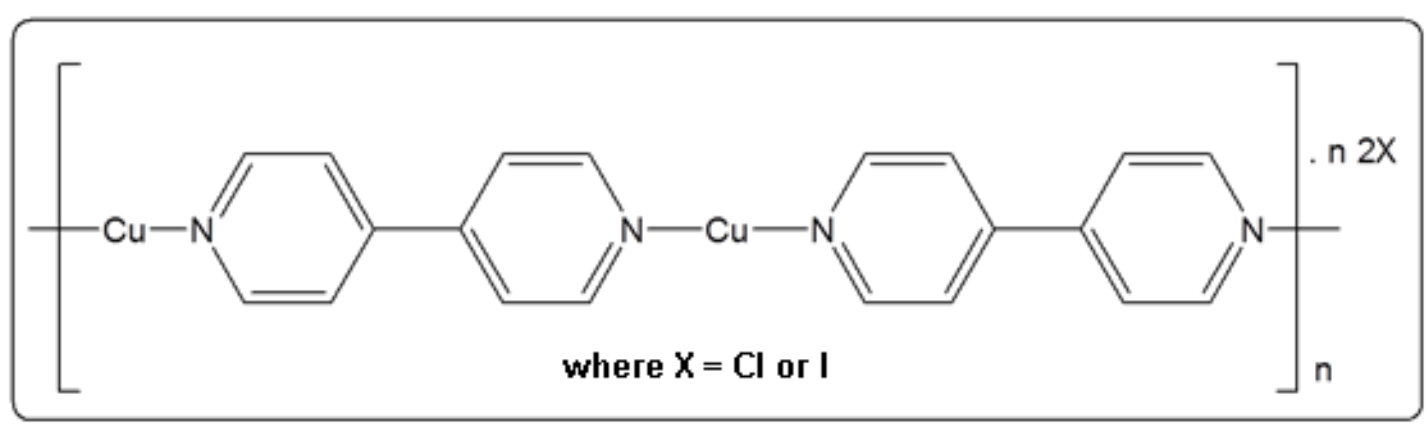

Figure 2. Structure proposed for the $\left[\mathrm{Cu}\left(4,4^{\prime}\right.\right.$-dipy $\left.)\right] \mathrm{Cl}$ complex from the data of infrared spectroscopic and elemental analysis.

After the synthesis and characterization of copper(I) complexes, the 1,4-disubstituted 1,2,3triazole were synthesized. The result was then analyzed by ${ }^{1} \mathrm{H}$ NMR and demonstrated the following signals: a singlet at $8.64 \mathrm{ppm}$ referring to the H-triazolic multiples between 7.87 and 7.32 ppm, referring to the protons of the aromatic ring, and two triplets referring to the alkyl groups, the first being at $4.75 \mathrm{ppm}$, and the second at $4.21 \mathrm{ppm}$. The ${ }^{13} \mathrm{C}$ NMR spectrum makes it possible to 
observe a signal at 167.6, referring to the carbonyls and a signal at 148.0 referring to the carbon on the triazolic ring, signals between 134.2 and 119.8 referring to the aromatic carbons; and two signals at 47.8 and 37.6 referring to the alkyl carbons.
These results indicate that the desired triazole had been synthesized and the ${ }^{1} \mathrm{H}$ and ${ }^{13} \mathrm{C}$ NMR are in according with literature ${ }^{34}$.

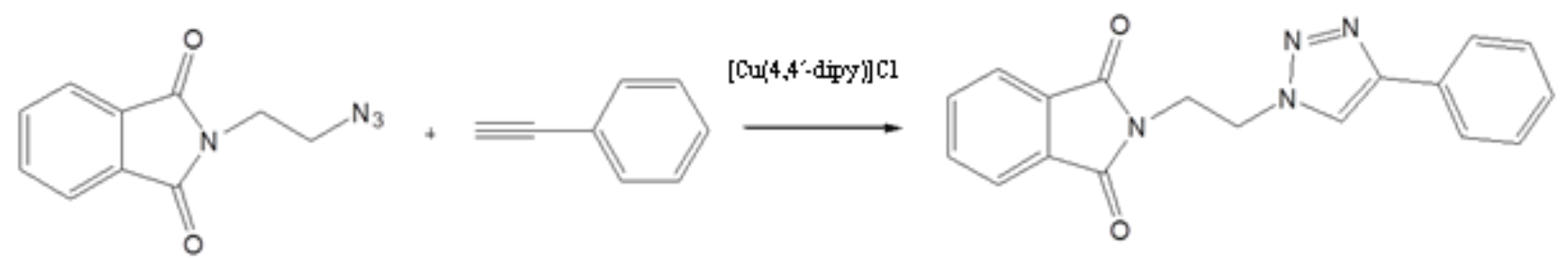

Scheme 1. Synthesis of 1,2,3-triazole catalyzed by [Cu(4,4'-dipy) $] \mathrm{Cl}$ complex.

2-[2-(4-Phenyl-[1,2,3]triazol-1-yl)-ethyl]isoindole-1,3-dione: ${ }^{1} \mathrm{H}$ NMR (400 MHz, DMSO$\left.d_{6}\right): \delta 8.64\left(\mathrm{~s}, 1 \mathrm{H}, \mathrm{H}_{\text {triaz }}\right), 7.87-7.82(\mathrm{~m}, 4 \mathrm{H}, \mathrm{Phth})$, $7.77\left(\mathrm{~d}, 2 \mathrm{H}, J=8.0 \mathrm{~Hz}, \mathrm{H}_{\text {arom }}\right), 7.43(\mathrm{dd}, 2 \mathrm{H}, J=$ 7.6, 7.6 Hz, $\left.\mathrm{H}_{\text {arom }}\right), 7.32(\mathrm{dd}, 1 \mathrm{H}, J=7.6,7.6 \mathrm{~Hz}$, $\left.\mathrm{H}_{\text {arom }}\right), 4.69\left(\mathrm{t}, 2 \mathrm{H}, J=6.0 \mathrm{~Hz}, \mathrm{NCH}_{2}\right), 4.06(\mathrm{t}, 2 \mathrm{H}$, $\left.J=5.6 \mathrm{~Hz}, \mathrm{NCH}_{2}\right) .{ }^{13} \mathrm{C} \mathrm{NMR}\left(75.5 \mathrm{MHz}, \mathrm{CDCl}_{3}\right)$ : $\delta$ 37.6, 47.8, 119.8, 123.5, 125.7, 128.1, 128.7, 130.3, 131.6, 134.2, 148.0, 167.6.

The copper (I) chloride and iodide were used to make the same synthesis in order to compare their catalytic capacity with regard to copper(I) complexes. After $23 \mathrm{~h}$, the azide has been completely consumed and the mixture which had suffered reaction was then treated with $\mathrm{NH}_{4} \mathrm{OH}$ to remove the copper residues. When copper (I or II) salts are used, the $\mathrm{NH}_{4} \mathrm{OH}$ extraction step is always necessary, which generates soluble copper residues in the water, leading to a greater environmental contamination. The yield on the synthesis obtained by using copper (I) chloride with or without a base were $38.4 \%$ and $16.3 \%$, respectively. With copper (I) iodide, with or without a base, they were $92.8 \%$ and $54.8 \%$, respectively.

In the synthesis using $\left[\mathrm{Cu}\left(4,4^{\prime}\right.\right.$ '-dipy $\left.)\right] \mathrm{Cl}$ complex, the reaction time varied between 19 and $22 \mathrm{~h}$. In all the cases, the catalyst was removed by centrifugation process, eliminating the extraction step with $\mathrm{NH}_{4} \mathrm{OH}$. The synthesis using a base lead to improved the yield, but not enough to justify their use. Table 2 shows the reaction yields with $[\mathrm{Cu}(4,4$ '-dipy) $] \mathrm{Cl}$ complex, with or without addition of base. On the other hand, the same reaction using [ $\mathrm{Cu}\left(4,4^{\prime}\right.$ '-dipy)]I complex even after it has been stirred for $48 \mathrm{~h}$, did not promoted the formation of the desired product.

Table 2. Yields for the synthesis of 1,2,3-triazole in the presence or absence of base catalyzed by $\mathrm{CuCl}, \mathrm{CuI},\left[\mathrm{Cu}\left(4,4^{\prime}-\right.\right.$ dipy $\left.)\right] \mathrm{Cl}$ and $\left[\mathrm{Cu}\left(4,4^{\prime}\right.\right.$-dipy $\left.)\right] \mathrm{Cl}$ complexes

\begin{tabular}{llllllll}
\hline \multicolumn{2}{l}{ Reaction Yield (\%) } & & & & & \\
\hline CuCl & CuI & & \multicolumn{2}{l}{$\left[\mathbf{C u}\left(\mathbf{4}, \mathbf{4}^{\prime}\right.\right.$-dipy) $] \mathrm{Cl}$} & \multicolumn{2}{l}{$\left[\mathbf{C u}\left(\mathbf{4}, \mathbf{4}^{\prime}\right.\right.$-dipy) $\mathbf{I}$} \\
$\mathbf{E t}_{3} \mathbf{N}^{*}$ & No Base & $\mathbf{E t}_{3} \mathbf{N}^{*}$ & No Base & $\mathbf{E t}_{3} \mathbf{N}^{*}$ & No Base & $\mathbf{E t}_{3} \mathbf{N}^{*}$ & No Base \\
\hline 38.4 & 16.3 & 92.8 & 54.8 & $\mathbf{8 8 . 0}$ & $\mathbf{7 0 . 0}$ & $0 \%$ & $0 \%$ \\
\hline
\end{tabular}

* $\mathrm{Et}_{3} \mathrm{~N}=$ triethylamine.

In order to evaluate the capacity for reuse of the catalyst $([\mathrm{Cu}(4,4$ '-dipy $)] \mathrm{Cl}$ complex $)$, the reaction was repeated five times, recovering the catalyst by centrifugation and adjusting the amount of reagents (azide and alkyne). Before reuse, the catalyst was washed $(5 \mathrm{x})$ with dichloromethane to remove possible interferents. When triethylamine was used, after 5 cycles of reactions, the yield decreased to $33.5 \%$ (Table 3, cycle 5). In the case of reactions which did not use the base, the yields lessened to $49.8 \%$ after five cycles. 
Table 3. Recycling Steps of $\left[\mathrm{Cu}\left(4,4^{\prime}-\right.\right.$ dipy $\left.)\right] \mathrm{Cl}$ complex

\section{[Cu(4,4'-dipy)]Cl / Reaction Yield (\%)}

\begin{tabular}{lll} 
Cycle & $\mathbf{E t}_{3} \mathbf{N}^{*}$ & No Base \\
$\mathbf{1}$ & 88.0 & 70.0 \\
$\mathbf{2}$ & 78.8 & 68.9 \\
$\mathbf{3}$ & 66.6 & 66.5 \\
$\mathbf{4}$ & 59.9 & 63.0 \\
$\mathbf{5}$ & 33.5 & 49.8 \\
$\mathbf{6}^{\mathbf{a}}$ & 86.4 & 71.9 \\
\hline
\end{tabular}

${ }^{\mathrm{a}}$ After added ascorbic acid (10 mol \%).

To explain our poor results after five cycles, however, we need to have some considerations. The viability of the reductive elimination process (restitution of the copper to its lowest value oxidative) and the quality of the solvents used (type of oxidants present). Supposing the copper (II) generation, which would justify the reduction of active sites, $\mathrm{Cu}(\mathrm{I})$, as a reaction promoter, ascorbic acid was used as a reducing agent for recuperation of the catalyst. In both cases, with or without the use of a base, after use of ascorbic acid, the yields were restored. In the case of the drastic lessening of yields when trietilamine was used, it can be accounted for because of the base, before acting as a depronate of alkyne and after oxidation of copper (I) to the form (II), could be added as a ligant in the coordiation sphere of the first cupric ion, since the typical coordination numbers of these ions copper (I) and (II) are 2 and 4, respectively. The Scheme 2 shows the mechanism proposed to create the reaction using $[\mathrm{Cu}(4,4$ '-dipy $)] \mathrm{Cl}$ complex.

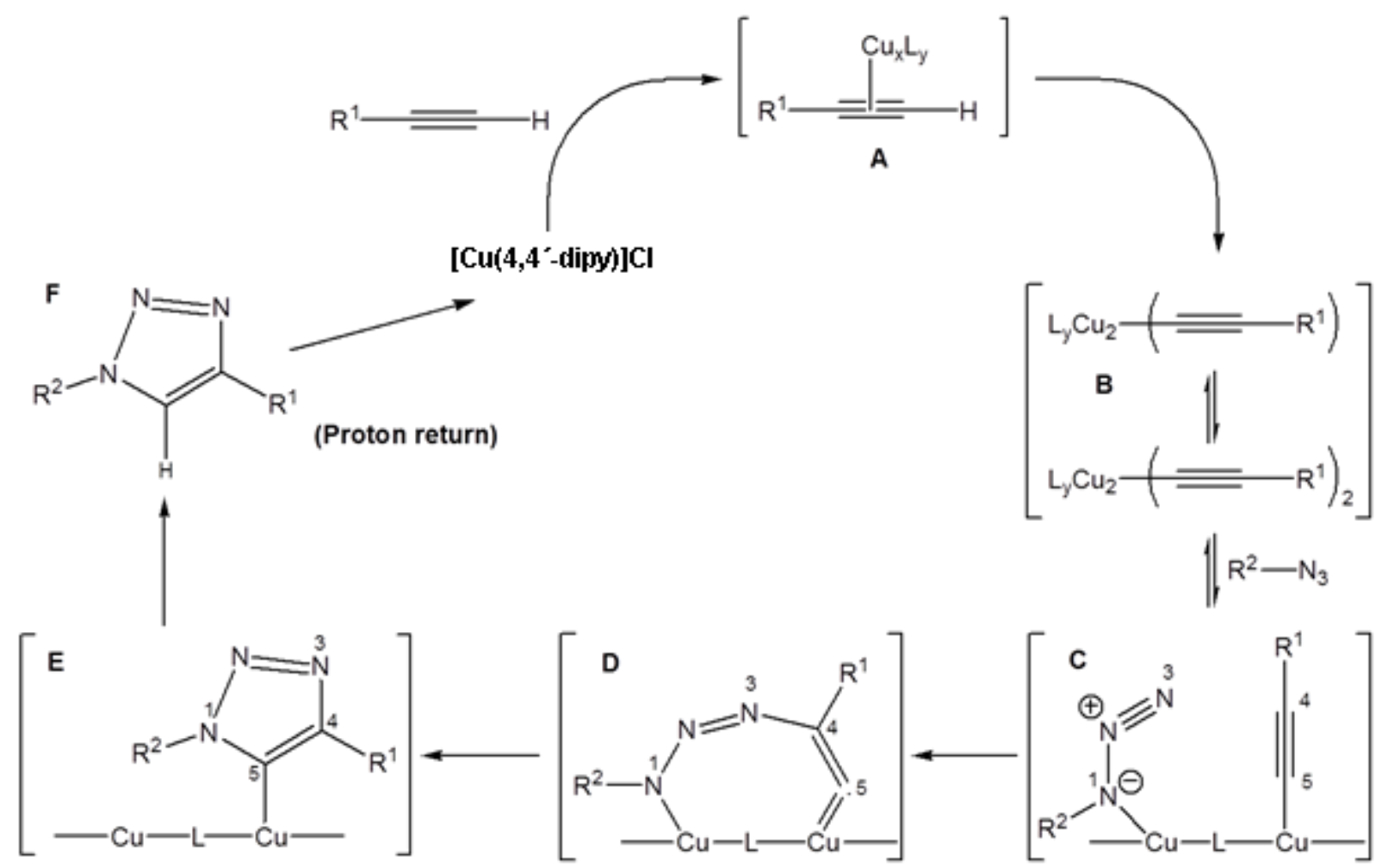

Scheme 2. Mechanism proposed for the Huisgen cycloaddition reaction mediated by [Cu(4,4'-dipy)]Cl complex.

Based on data in literature indicating that $\mathrm{Cu}(\mathrm{I})$ catalyzed alkyne-azide coupling begins with $\pi$ complex A (Scheme 2), this first step was also proposed for the $[\mathrm{Cu}(4,4$ '-dipy $)] \mathrm{Cl}$ complex ${ }^{30-36}$. Some works suggest that an energetic compensation can occur depending on the solvent 
used in this reaction, i.e. an improvement can be perceived, concerning copper species formation $\mathbf{B}$ (Scheme 2), and then this copper coordination can reduce the $\mathrm{C}-\mathrm{H}$ alkyne $\mathrm{pK}_{\mathrm{a}}$, facilitating the deprotonation in aqueous systems without the use of a base ${ }^{37}$. In the case of the current work, the reaction was carried out, using dichloromethane $\left(\mathrm{CH}_{2} \mathrm{Cl}_{2}\right)$ as the solvent, in the presence and absence of the base (triethylamine), in both cases the final product was obtained with yields of $(88 \%)$ and $(70 \%)$, respectively. This last reactional condition, using $\mathrm{CH}_{2} \mathrm{Cl}_{2}$, invites more significant studies, experimental and/or theoretical, involving different solvents and their interference on the catalytic cycle. In comparison with the usual mechanistic studies ${ }^{37-39}$, the current $\left[\mathrm{Cu}\left(4,4^{\prime}\right.\right.$ dipy)]I complex reinforces and represent well the requirement of two catalytic copper atoms, here can be spaced by a 4,4'-dipyridyl ligand, which were part of an alkyne-azide cycloaddition. The first one changed the alkyne (acetylide complex) reaction and the second served as an azide activator which led to the $\mathbf{D}$ cyclization (Scheme 2).

Some works have suggested that the size of the ring which surrounds the two acid centers of copper D may be easily converted into a copper triazole ring $\mathbf{E}$ (Scheme 2) ${ }^{37}$. There is a considerable need for experimental work to confirm the true proton source responsible for the protonation of the type shown in $\mathbf{E}$, which will converge on the composite $\mathbf{F}$, which may be the reaction which occurs in the presence or absence of a base ${ }^{40,41}$. Even with the extensive use of copper salts capable of catalyzing alkyne-azide coupling reactions, the anions of which generally look like sulfate and halogens (generally $\mathrm{Cl}, \mathrm{Br}$ and I), the study of the influence of these anions as reactors have not been entirely understood by the scientific community. Thus we must emphasize that in the present study, the use of metalorganic compounds, $\left[\mathrm{Cu}\left(4,4^{\prime}\right.\right.$-dipy $\left.)\right] \mathrm{Cl}$ and $[\mathrm{Cu}(4,4$ '-dipy $)] \mathrm{I}$ complexes, synthesized from the known types of copper salts, $\mathrm{CuCl}$ and $\mathrm{CuI}$ respectively, showed that the reaction yield was extremely dependent on the anion present in these complexes. In other words, the difference of these counter-ions (anions) present in the complexes were the determining factor as to the catalytic force of the same, making the type $[\mathrm{Cu}(4,4$ '-dipy $)] \mathrm{I}$ complex not viable for catalyzing the reaction proposed in this study (Scheme 1). Further studies need to be made to confirm which anions work best for high yields in copper(I)-catalyzed reaction.

\section{Conclusions}

The copper(I) complexes compounds were synthesized and characterized by elemental analysis and infrared spectroscopy; and applied as catalysts in the Huisgen reaction. There was a high yield from the reactions catalyzed by $\mathrm{CuI}(92.8 \%)$ and $[\mathrm{Cu}(4,4$ '-dipy) $] \mathrm{Cl}$ complex $(96 \%)$. In the case of the same reaction catalyzed by $\mathrm{CuCl}(38 \%)$ the yields were low. No product was obtained using $\left[\mathrm{Cu}\left(4,4^{\prime}\right.\right.$ '-dipy $\left.)\right] \mathrm{I}$ complex. Reuse of the $\left[\mathrm{Cu}\left(4,4^{\prime}\right.\right.$ dipy)]Cl catalyst was proven through a cycle of five consecutive syntheses, resulting in the desired product. The yield from the reactions, however, diminished gradually. The synthetic cycle's maintainer the same reactive good yields through a process of copper (II) ion reduction, which had generated in the complex structure after used ascorbic acid, justifying the preferential use of this matrix as the catalyst in Huisgen 1,3-dipolar cycloaddition reaction.

\section{References}

[1] Chen, J.C., Luo, W.Q., Wang, H.D., Xiang, J.M., Jin, H.F., Chen, F., Cai, Z.W., A versatile method for the preparation of end-functional polymers onto $\mathrm{SiO} 2$ nanoparticles by a combination of surface-initiated ATRP and Huisgen [3 + 2] cycloaddition, Applied Surface Science $256 \quad$ (8) (2010) 2490-2495. https://doi.org/10.1016/j.apsusc.2009.10.093.

[2] Li, H., Eddaoudi, M., O'Keeffe, M., Yaghi, O.M., Design and synthesis of an exceptionally stable and highly porous metal-organic framework,

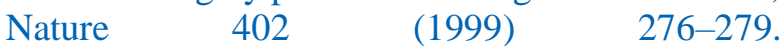
https://doi.org/10.1038/46248.

[3] Rowsell, J.L.C., Yaghi, O. M., Metal-organic frameworks: a new class of porous materials, Micropor. Mesopor. Mater. 73 (1-2) (2004) 3-14. https://doi.org/10.1016/j.micromeso.2004.03.034.

[4] Li, Z.-Q., Qiu, L.-G., Xu, T., Wu, Y., Wang, W., Wu, Z.-Y., Jiang, X., Ultrasonic synthesis of the microporous metal-organic framework $\mathrm{Cu} 3$ (BTC)2 at ambient temperature and pressure: An efficient and environmentally friendly method, Mater. Lett. 63 (1) (2009) 78-80. https://doi.org/10.1016/j.matlet.2008.09.010. 
[5] Dhakshinamoorthy, A., Alvaro, M., Corma, A., Garcia, H., Delineating similarities and dissimilarities in the use of metal organic frameworks and zeolites as heterogeneous catalysts for organic reactions, Dalton Trans. 40 (2011) 6344-6360. https://doi.org/10.1039/c1dt10354g.

[6] Phan, N. T. S., Le, K. K. A., Phan, T. D., MOF5 as an efficient heterogeneous catalyst for FriedelCrafts alkylation reactions, Appl. Catal. A: Gen. 382 (2) (2010) 246-253. https://doi.org/10.1016/j.apcata.2010.04.053.

[7] Ravon, U., Savonnet, M., Aguado, S., Domine, M.E., Janneau, E., Farrusseng, D., Engineering of coordination polymers for shape selective alkylation of large aromatics and the role of defects, Micropor. Mesopor. Mater. 129 (3) (2010) 319-329.

https://doi.org/10.1016/j.micromeso.2009.06.008.

[8] Nguyen, L. T. L., Nguyen, C. V., Dang, G. H., Le, K. K. A., Phan, N. T. S., Towards applications of metal-organic frameworks in catalysis: FriedelCrafts acylation reaction over IRMOF-8 as an efficient heterogeneous catalyst, J. Mol. Catal. A. Chem. $349 \quad(1-2) \quad$ (2011) 28-35. https://doi.org/10.1016/j.molcata.2011.08.011.

[9] Dhakshinamoorthy, A., Alvaro, M., Garcia, H., Aerobic Oxidation of Benzylic Alcohols Catalyzed by Metal-Organic Frameworks Assisted by TEMPO, ACS Catal. 1 (1) (2011) 48-53. https://doi.org/10.1021/cs1000703.

[10] Xamena, F. X. L. I., Casanova, O., Tailleur, R. G., Garcia, A. C. H., Metal organic frameworks (MOFs) as catalysts: A combination of $\mathrm{Cu}^{2+}$ and $\mathrm{Co}^{2+}$ MOFs as an efficient catalyst for tetralin oxidation, J. Catal. 255 (2) (2008) 220-227. https://doi.org/10.1016/j.jcat.2008.02.011.

[11] Liu, H., Liu, Y., Li, Y., Tang, Z., Jiang, H., Metal-Organic Framework Supported Gold Nanoparticles as a Highly Active Heterogeneous Catalyst for Aerobic Oxidation of Alcohols, J. Phys. Chem. C 114 (2010) 13362-13369. https://doi.org/10.1021/jp105666f.

[12] Kleist, W., Maciejewski, M., Baiker, A., MOF-5 based mixed-linker metal-organic frameworks: Synthesis, thermal stability and catalytic application, Thermochim. Acta 499 (1-2)
(2010)

$71-78$.

https://doi.org/10.1016/j.tca.2009.11.004.

[13] Dhakshinamoorthy, A., Alvaro, M., Garcia, H., Metal organic frameworks as efficient heterogeneous catalysts for the oxidation of benzylic compounds with t-butylhydroperoxide, J. Catal. $267 \quad$ (1) (2009) 1-4. https://doi.org/10.1016/j.jcat.2009.08.001.

[14] Wang, W., Li, Y., Zhang, R., He, D., Liu, H., Liao, S., Metal-organic framework as a host for synthesis of nanoscale $\mathrm{Co} 3 \mathrm{O} 4$ as an active catalyst for CO oxidation, Catal. Commun. 12 (10) (2011) 875-879.

https://doi.org/10.1016/j.catcom.2011.02.001.

[15] Song, F., Wang, C., Falkowski, J. M., Ma, L., Lin, W., Isoreticular Chiral Metal-Organic Frameworks for Asymmetric Alkene Epoxidation: Tuning Catalytic Activity by Controlling Framework Catenation and Varying Open Channel Sizes, J. Am. Chem. Soc. 132 (43) (2010) 1539015398. https://doi.org/10.1021/ja1069773.

[16] Cho, S.-H., Ma, B., Nguyen, S. T., Hupp, J. T., Albrecht-Schmitt, T. E., A metal-organic framework material that functions as an enantioselective catalyst for olefin epoxidation, Chem. Commun. (24) (2006) 2563-2565. https://doi.org/10.1039/B600408C.

[17] Brown, K., Zolezzi, S., Aguirre, P., VenegasYazigi, D., Paredes-García, V., Baggio, R., Novak, M. A., Spodine, E., $[\mathrm{Cu}(\mathrm{H} 2 \mathrm{btec})($ bipy) $] \circ$ : a novel metal organic framework (MOF) as heterogeneous catalyst for the oxidation of olefins, Dalton Trans. (2009) 1422-1427. https://doi.org/10.1039/B810414J.

[18] Opelt, S., Turk, S., Dietzsch, E., Henschel, A., Kaskel, S., Klemm, E., Preparation of palladium supported on MOF-5 and its use as hydrogenation catalyst, Catal. Commun. 9 (2008) 1286-1290. https://doi.org/10.1016/j.catcom.2007.11.019.

[19] Xamena, F. X. L. I., Abad, A., Corma, A., Garcia, H., MOFs as catalysts: Activity, reusability and shape-selectivity of a Pd-containing MOF, J. Catal. $\quad 250 \quad$ (2007) 294-298. https://doi.org/10.1016/j.jcat.2007.06.004. 
[20] Huang, Y., Zheng, Z., Liu, T., Lü, J., Lin, Z., Li, H., Cao, R., Palladium nanoparticles supported on amino functionalized metal-organic frameworks as highly active catalysts for the Suzuki-Miyaura cross-coupling reaction, Catal. Commun. 14 (2011) 27-31. https://doi.org/10.1016/j.catcom.2011.07.004.

[21] Gao, S., Zhao, N., Shu, M., Che, S., Palladium nanoparticles supported on MOF-5: A highly active catalyst for a ligand- and copper-free Sonogashira coupling reaction, Appl. Catal. A: Gen. $\quad 388 \quad$ (2010) 196-201. https://doi.org/10.1016/j.apcata.2010.08.045.

[22] Zhou, Y., Song, J., Liang, S., Hu, S., Liu, H., Jiang, T., Han, B., Metal-organic frameworks as an acid catalyst for the synthesis of ethyl methyl carbonate via transesterification, J. Mol. Catal. A 308 (2009) 68-75. https://doi.org/10.1016/j.molcata.2009.03.027.

[23] Neogi, S., Sharma, M. K. and Bharadwaj, P. $\mathrm{K}$., Knoevenagel condensation and cyanosilylation reactions catalyzed by a MOF containing coordinatively unsaturated $\mathrm{Zn}$ (II) centers, J. Mol. Catal. A 299 (1-2) (2009) 1-4. https://doi.org/10.1016/j.molcata.2008.10.008.

[24] Gascon, J., Aktay, U., Hernandez-Alonso, M. D., Klink, G. P. M. V., Kapteijn, F., Amino-based metal-organic frameworks as stable, highly active basic catalysts, J. Catal. 261 (2009) 75-87. https://doi.org/10.1016/j.jcat.2008.11.010.

[25] Oxford, G. A. E., Dubbeldam, D., Broadbelt, L. J., Snurr, R. Q., Elucidating steric effects on enantioselective epoxidation catalyzed by (salen)Mn in metal-organic frameworks, J. Mol. Catal. A. Chem. 334 (1-2) (2011) 89-97. https://doi.org/10.1016/j.molcata.2010.11.001.

[26] Dewa, T., Saiki, T., Aoyama, Y., Enolization and Aldol Reactions of Ketone with a La3+Immobilized Organic Solid in Water. A Microporous Enolase Mimic, J. Am. Chem. Soc. 123 (2001) 502-503. https://doi.org/10.1021/ja001140b.

[27] Vermoortele, F., Ameloot, R., Vimont, A., Serre, C., Vos, D. D., An amino-modified Zrterephthalate metal-organic framework as an acidbase catalyst for cross-aldol condensation, Chem.
Commun. $47 \quad$ (5) (2011) 1511-1523. https://doi.org/10.1039/C0CC03038D.

[28] Luz, I., Xamena, F. X. L. I., Corma, A., Bridging homogeneous and heterogeneous catalysis with MOFs: "Click" reactions with $\mathrm{Cu}-$ MOF catalysts, J. Catal. 276 (2010) 134-140. https://doi.org/10.1016/j.jcat.2010.09.010.

[29] Luz, I., Xamena, F. X. L. I., Corma, A., Bridging homogeneous and heterogeneous catalysis with MOFs: $\mathrm{Cu}-\mathrm{MOF}$ as solid catalysts for three-component coupling and cyclization reactions for the synthesis of propargylamines, indoles and imidazopyridines, J. Catal. 285 (2012) 285-291.

https://doi.org/10.1016/j.jcat.2011.10.001.

[30] Rostovtsev, V. V., Green, L. G., Fokin, V. V., Sharpless, K. B., Angew. A Stepwise Huisgen Cycloaddition Process: Copper(I)-Catalyzed Regioselective "Ligation" of Azides and Terminal Alkynes, Chem. Int. Ed. 41 (2002) 2596 - 2599. https://doi.org/10.1002/15213773(20020715)41:14\%3C2596::AIDANIE2596\%3E3.0.CO;2-4.

[31] Tornøe, C. W., Christensen, C., Meldal, M., Peptidotriazoles on Solid Phase: [1,2,3]-Triazoles by Regiospecific Copper(I)-Catalyzed 1,3-Dipolar Cycloadditions of Terminal Alkynes to Azides, J. Org. Chem. $67 \quad$ (2002) 3057-3064. https://doi.org/10.1021/jo011148j.

[32] da Silva, M. T., de Oliveira, R. N., Valença, W. O., Barbosa, F. C. G., da Silva, M. G., Camara, C.A., Synthesis of N-Substituted Phthalimidoalkyl 1H-1,2,3-Triazoles: A Molecular Diversity Combining Click Chemistry and Ultrasound Irradiation, J. Braz. Chem. Soc. 23 (2012) 1839 $1843 . \quad$ https://doi.org/10.1590/S010350532012005000053.

[33] Barbosa, F. C. G., de Oliveira, R. N., Synthesis of a New Class of Triazole-Linked Benzoheterocycles via 1,3-Dipolar Cycloaddition, J. Braz. Chem. Soc. 22 (2011) 592-597. https://doi.org/10.1590/S010350532011000300025.

[34] Sirion U., Lee, J. H., Bae, Y. J., Kim, H. J., Lee, B. S., Chi, D. Y., Azide/alkyne resins for quick preparation of 1,4-disubstituted 1,2,3- 
triazoles, Bull. Korean Chem. Soc. 31 (2010) 18431847.

https://doi.org/10.5012/bkcs.2010.31.7.1843.

[35] For a review of transition metal-catalyzed acetylenic coupling, see: Siemsen, P., Livingston, R. C. and Diederich, F., Acetylenic Coupling: A Powerful Tool in Molecular Construction, Angew. Chem. Int. Ed. 39 (2000) 2632-2657. https://doi.org/10.1002/1521-

3773(20000804)39:15<2632::AID-

ANIE2632>3.0.CO;2-F.

[36] For a common example, see: Sonogashira, K., Tohda, Y., Hagihara, N., A convenient synthesis of acetylenes: catalytic substitutions of acetylenic hydrogen with bromoalkenes, iodoarenes and bromopyridines, Tetrahedron Lett. 16 (1975) 4467 - $\quad 4470 . \quad$ https://doi.org/10.1016/S00404039(00)91094-3.

[37] Himo, F., Lovell, T., Hilgraf, R., Rostovtsev, V. V., Noodleman, L., Sharpless, K. B., Fokin, V. V., Copper(I)-Catalyzed Synthesis of Azoles. DFT Study Predicts Unprecedented Reactivity and Intermediates, J. Am. Chem. Soc. 127 (2005) 210216. https://doi.org/10.1021/ja0471525.

[38] J. Bastide, O. Henri-Rousseau, in Chemistry of the Carbon-Carbon Triple Bond (Ed.: S. Patai), Interscience Publishers, London, 1978, p. 447-552.

[39] Collman, J. P., Devaraj, N. K., Chidsey, C. E. D., "Clicking" Functionality onto Electrode Surfaces, Langmuir 20 (2004) 1051-1053. https://doi.org/10.1021/la0362977.

[40] Rodinov, V. O., Fokin, V. V., Finn, M. G., Mechanism of the ligand-free CuI-catalyzed azidealkyne cycloaddition reaction, Angew. Chem. Int. Ed. 44 (2005) 2210-2215. https://doi.org/10.1002/anie.200461496.

[41] Bock, V. D., Hiemstra, H., Maarseveen, J. H., CuI-Catalyzed Alkyne-Azide "Click" Cycloadditions from a Mechanistic and Synthetic Perspective, Eur. J. Org. Chem. (2006) 51-68. https://doi.org/10.1002/ejoc.200500483. 